\title{
Fracture Surface Fractal Characteristics of Alkali-Slag Concrete under Freeze-Thaw Cycles
}

\author{
Wantong Cai, Guoping Cen, and Haifu Wang \\ Department of Airfield and Building Engineering, Air Force Engineering University, Xian, Shaanxi 710038, China \\ Correspondence should be addressed to Haifu Wang; 376404958@qq.com
}

Received 18 March 2017; Accepted 22 May 2017; Published 18 June 2017

Academic Editor: Francisca Puertas

Copyright (C) 2017 Wantong Cai et al. This is an open access article distributed under the Creative Commons Attribution License, which permits unrestricted use, distribution, and reproduction in any medium, provided the original work is properly cited.

\begin{abstract}
Fractal theory is introduced in fracture surface research of alkali-slag concrete (ASC) under freeze-thaw cycles; crack distribution of ASC fracture surface and freeze-thaw damage zone were calculated. Through fractal analysis of ASC sample fracture surfaces, relevance between section fractal dimension and fracture toughness and relationship between material composition and section fractal dimension are clarified. Results show that the specimen's cracks before freeze-thaw extend along force direction gently, and there are more twists and turns after freezing and thawing; the fractal dimension $D$ also grows from 1.10 to 1.33. SEM internal microcracks' $D$ of ASC internal microstructure after freezing and thawing is 1.37; 0 to 300 times ASC fractal dimension under freezing and thawing is between 2.10 and 2.23; with freeze-thaw times increasing, ASC fracture toughness decreases and fractal dimension increases, the fractal dimension and fracture toughness have a good linear relationship, and the fractal dimension can reflect the toughening effect of ASC. It is very feasible to evaluate ASC fracture behaviour under freezing and thawing with the fractal theory. Fractal dimension generally increases with activator solution-slag (A/S for short) or slag content. The greater the amount of $\mathrm{A} / \mathrm{S}$ or slag content, the lower the dimension.
\end{abstract}

\section{Introduction}

ASC is a new green concrete material, attracting a lot of research. Meanwhile, using fractal theory in concrete material is becoming a hotspot in civil engineering. Fractal geometry is a branch of mathematics developed by a French-American scientist, Mandelbrot, in the 1970s [1]. Fractal theory is an effective way to describe material characteristics such as self-similar in micro-, meso-, and macrolevels and is an effective way to explore the physical and mechanical behaviour of different levels of the fine structure and macrofield performance. Through research on material microstructure changes, Hadjileontiadis and Douka [2] believe the fractal theory can be used to describe characterizations such as development of material cracks and depth; Mecholsky Jr. [3] considered that various fracture parameters of brittle materials can be represented by fractal dimension; He and Yang [4] introduced the pore structure of ASC using fractal theory; Yan et al. $[5,6]$ think that the fracture process of concrete also has fractal characteristics, its macroscopic mechanical properties degradation is associated with crack (i.e., damage) development, by means of fractal analysis, and concrete micro- and macroscale information can be grasped more reasonably and accurately.

The fractal research on fracture surface began in the mid1980s. Saouma et al. [7] first studied the fractal nature of concrete fracture surface and found that the fractal dimension of concrete fracture surface changes from 1.10 to 1.20 ; Issa and Hammad [8] also investigated concrete fracture surface, obtaining similar results; Nagahama [9] established the unified relationship between fracture toughness and fractal dimension $D$ based on numerous studies. Through experiments, Yan et al. found that using fractal dimension to reflect concrete fracture energy is feasible. With water-cement ratio increasing, the fractal dimension will also increase. By fitting the experimental data, Yan et al. got the relationship between fractal dimension and fracture energy [5] and calculated the fractal dimension of concrete fracture surface using laser method [10]; Issa et al. [11] found that a clear correlation exists between fractal dimension and fracture toughness: the tougher the material, the higher the fractal dimension. Vidya Sagar and Raghu Prasad [12] used singular fractal functions 
to generate stress-strain plots for quasi-brittle material like concrete and cement mortar. Fu et al. [13] studied the ASC damage model under freeze-thaw cycles; Šejnoha et al. [14] summarized the fracture toughness of concrete for tunnel lining; Cai et al. [15] studied the ASC antifreeze durability; Sun and $\mathrm{Wu}$ [16] investigated the chemical properties and frost resistance of fly ash inorganic mixture; Li et al. [17] studied fractal characteristics of concrete fracture surface before and after freezing and thawing and applied fractal theory to study freeze-thaw damage; results show that the fracture toughness and fractal dimension have a good correlation, so fractal theory and concrete fracture theory can be combined to evaluate the fracture behaviour of concrete under freezethaw cycles; Zhang [18] suggested that when concrete fracture surface fractal dimension increases, the fracture toughness will also increase and that the fracture surface roughness increases the material anticracking ability; Guo et al. concluded application of fractal theory in concrete material mechanical behaviour, distribution of aggregates, concrete fracture toughness and fracture energy, pore, concrete material acoustic emission, and many other aspects of application $[19,20]$. Erdem and Blankson [21] determined quantitatively the fractal character and texture of fracture surfaces and investigated their influence on the fracture-related properties in different types of concrete. Konkol and Prokopski [22] studied fracture toughness of concrete with metakaolinite additive, drawing the conclusion that fracture toughness correlates with fractal dimension and water/binder ratio.

Application of fractal theory in concrete provides a new way for concrete research, but there are few researches on the application of fracture theory for ASC antifrost durability. Measuring fracture surface fractal dimension is an important aspect of ASC fracture surface. It is necessary to obtain accurate fractal dimension before further exploring the relationship with other properties. The paper introduces fractal theory into fracture surface research of ASC under freeze-thaw cycles, as ASC surface crack and fracture surface graphics have good self-similar characteristics within a certain range; aimed at characteristics of two-dimensional digital image, crack distribution of ASC fracture surface and freeze-thaw damage zone are calculated. Through fractal analysis of ASC sample section, relationship between fracture surface fractal dimension and ASC fracture toughness and relationship between composition parameters and fractal dimension are clarified; fractal law of ASC specimen fracture surface and crack under freeze-thaw cycles is discussed.

\section{Experiment Materials and Methods}

2.1. Raw Materials and Specimen Preparation. The following material is used for making specimens: slag (specific surface is $410 \mathrm{~m}^{2} / \mathrm{kg}$ and density is $2.86 \mathrm{~g} / \mathrm{cm}^{3}$ ), alkali-activator composed of $\mathrm{NaOH}$ and $\mathrm{Na}_{2} \mathrm{SiO}_{3}$ (modulus is 3.34), river sand with density of $2.63 \mathrm{~g} / \mathrm{cm}^{3}$ and cumulate density of $1.50 \mathrm{~g} / \mathrm{cm}^{3}$, and limestone rubble $(5-20 \mathrm{~mm}, \sim 45 \% ; 20-$ $40 \mathrm{~mm}, \sim 55 \%)$ with density of $2.76 \mathrm{~g} / \mathrm{cm}^{3}$ and cumulate density of $1.59 \mathrm{~g} / \mathrm{cm}^{3}$. ASC mixture is mixed in a $60 \mathrm{~L}$ single horizontal axis mixer and the mixing process is as follows: sand

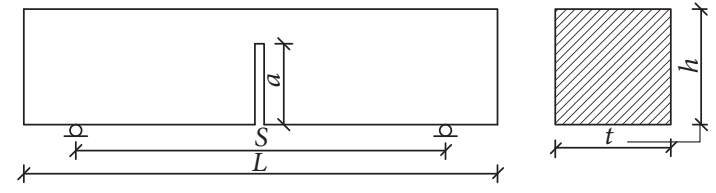

FIgURE 1: Fracture toughness test schema.

and slag (30 s) $\rightarrow$ stone (30 s) $\rightarrow$ activator solution (120 s) [15]. The mix proportions of ASC and test results of mixture's workability are shown in Table 1 . J. Lemaitre proposed that size of test-pieces applied to damage mechanics must reflect characteristics of materials. Thus, the test-pieces should be small enough so that they could avoid high gradient smooth and big enough so that they could reflect the average value of microprocess. Typical test-piece convenient for the study must satisfy these conditions. For concrete, size $100 \mathrm{~mm} \times$ $100 \mathrm{~mm} \times 400 \mathrm{~mm}$ is just convenient. GB/T 50082-2009 (standard test method for long-term performance and durability of ordinary concrete) and ASTM C666/C666 M-03 (standard test method for resistance of concrete to rapid freezing and thawing) also stipulate that size of test-piece for antifreeze experiment is $100 \mathrm{~mm} \times 100 \mathrm{~mm} \times 400 \mathrm{~mm}$. Prismoid in the size of $100 \mathrm{~mm} \times 100 \mathrm{~mm} \times 400 \mathrm{~mm}$ is used in the freezing-and-thawing experiment and damage mechanics analysis. Three-point bending beam with incision is used in the tests of study of concrete fracture parameters; the specimen size is shown in Figure 1. In Figure 1, the length of the specimen $L$ is $400 \mathrm{~mm}$, the span length $S$ is $300 \mathrm{~mm}$, and the sectional height $h$ and width $t$ are all $100 \mathrm{~mm}$, respectively, with initial notch-height ratio fixed at 0.4 .

2.2. Test Methods. Dynamic elastic modulus and mass loss of 5 groups (6 test-pieces for each group) are tested after different times of freeze-thaw cycle in the freezing-and-thawing experiment and damage mechanics analysis. Besides, each mix proportion moulded another 13 groups (3 test-pieces for each group), testing the compression strength, flexural strength, and fracture toughness after different times of freeze-thaw cycle. The test-pieces were placed in $20^{\circ} \mathrm{C}$ environment for 1 week after being shaped up. We transferred them to standard curing room immediately until reaching the test age. Then they were demoulded and numbered. Fault test uses 810 MTS material testing machine of MTS companies; the maximum load is $250 \mathrm{kN}$. Clip-on stretch instrument of type 3541 was used in the tests meeting the standard of ASTM E1820, E813, and E399.

The fracture toughness is calculated according to the method in DL/T 5332-2005 (norm for fracture test of hydraulic concrete) [23-25]. As the specimen size used in the test is nonstandard $(100 \mathrm{~mm} \times 100 \mathrm{~mm} \times 400 \mathrm{~mm})$, the fracture toughness got in tests is corrected standard specimen $(200 \mathrm{~mm} \times 120 \mathrm{~mm} \times 1000 \mathrm{~mm})$, according to DL/T 53322005 (norm for fracture test of hydraulic concrete) as follows:

$$
K_{\text {IC }}^{\text {sta }}=\left(\frac{V_{\text {sta }}}{V_{\text {non }}}\right)^{1 / \alpha}\left(\frac{h_{\text {sta }}}{h_{\text {non }}}\right)^{1 / 2} K_{I C}^{\text {non }},
$$


TABLE 1: The mix proportions and workability of ASC.

\begin{tabular}{lccccc}
\hline Number & A1 & A2 & A3 & A4 & \\
\hline Slag content $\left(\mathrm{kg} / \mathrm{m}^{3}\right)$ & 440 & 420 & 400 & 400 & 400 \\
A/S (-) & 0.56 & 0.56 & 0.58 & 0.56 & 0.54 \\
Sand ratio (\%) & 34 & 34 & 34 & 34 & 34 \\
Slump (mm) & 205 & 197 & 193 & 172 & 130 \\
\hline
\end{tabular}

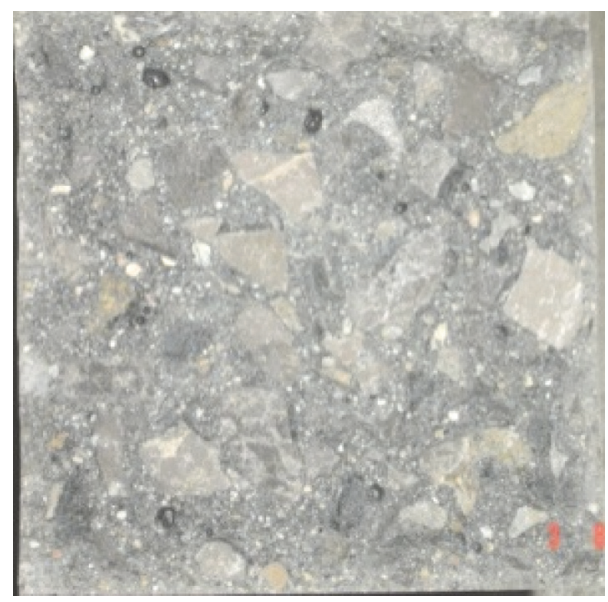

FIGURE 2: Prefreeze ASC fracture surface.

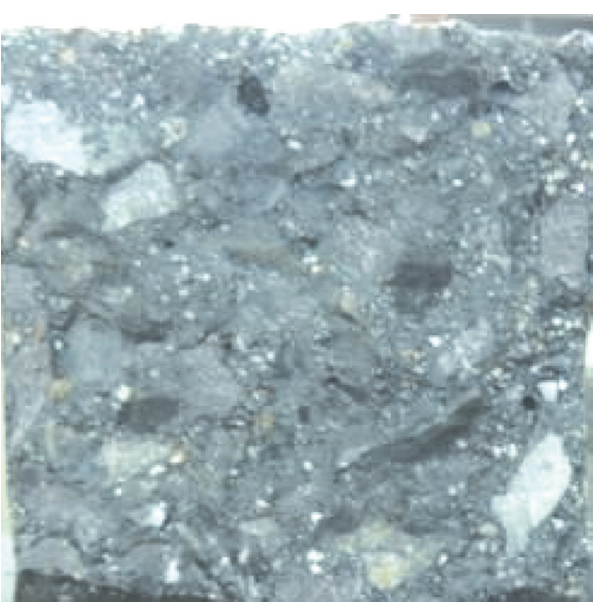

FIgure 3: Postthaw ASC fracture surface. where $K_{I C}^{\text {sta }}$ and $K_{I C}^{\text {non }}$ are, respectively, fracture toughness of standard and nonstandard method; $h_{\text {sta }}$ and $h_{\text {non }}$ are, respectively, height of specimen for standard $(0.2 \mathrm{~m})$ and nonstandard $(0.1 \mathrm{~m})$ method; $V_{\text {sta }}$ and $V_{\text {non }}$ are, respectively, volume of specimen for standard $\left(0.024 \mathrm{~m}^{3}\right)$ and nonstandard $\left(0.004 \mathrm{~m}^{3}\right)$ method; and $\alpha$ is Weibull parameter; it is generally advisable to take 7 13 for concrete, and 10 is taken in this paper [26].

\subsection{Test Results. Tests results are shown in Table 2.}

\section{Prefreeze and Postthaw ASC Fracture Surface Fractal Analysis}

3.1. Prefreeze and Postthaw ASC Fracture Surface. ASC fracture surfaces before and after freezing and thawing of concrete after fracture toughness test are shown in Figures 2 and 3. It can be seen from Figure 2 that fracture surface is relatively smooth before freezing and thawing, aggregate is mostly pulled off, and there are no significant cracks on the surface. It can be seen from Figure 3 that, due to internal damage after freezing and thawing, fracture toughness decreased severely, roughness of specimen and the fracture surface increased significantly, and the fracture surface aggregate declined completely. Because of the barrier of crack propagation in coarse aggregate, concrete fracture surface structure is very complex and has fractal characteristic. Therefore, fractal fracture surface is more suitable for the analysis of ASC after freezing and thawing.
3.2. Fractal Characteristic Analysis of ASC Fracture Surface. ASC macroscopic or microscopic cracks can be thought to be present in two-dimensional form (not to consider a threedimensional image), such as surface crack and internal injury. The two-dimensional image forms a curve after processing, on which we do this fractal study.

3.2.1. ASC Crack Fractal Digital Processing. With the development of information processing and computer technology, a large number of graphic images are obtained in the form of digital images or can be converted into a digital image. Fractal dimension is obtained by method of digital box dimension [27]. These digital images are different from traditional images carried by paper. Digital images are two-dimensional matrix represented by a series of binary digits ( 0 and 1$)$ after being sampled and quantized, which are with quantization and discrete features and have their characteristics in fractal dimension computing.

Digital images are formed by a series of pixels in a matrix form; pixels of different colors correspond to different values; for binary image (black and white bitmap) whose pixel is black or white, they are, respectively, represented as 1 or 0 in the matrix; then an image contains several submatrices containing 0 or 1 . If the area concerned contains 1 , mesh the whole matrix; the grid number can be counted, namely, the number of all nonzero submatrices; a descending sequence is constructed from

$$
\varepsilon_{k}=\left\{\frac{1}{c^{k-1}} \mid 0<k<\left[\frac{\ln w}{\ln c}\right]+1, k \in N\right\} .
$$


TABLE 2: Results of experiments and fracture surface fractal dimension under freeze-thaw cycles.

\begin{tabular}{|c|c|c|c|c|c|c|}
\hline Number & $\begin{array}{l}\text { Freeze-thaw } \\
\text { cycle times }\end{array}$ & $\begin{array}{c}\text { Dimension } \\
D\end{array}$ & $\begin{array}{c}\text { Correlation } \\
\text { coefficient } \\
R^{2}\end{array}$ & $\begin{array}{c}\text { Fracture } \\
\text { toughness } \\
\left(\mathrm{MPa} \cdot \mathrm{m}^{1 / 2}\right)\end{array}$ & $\begin{array}{l}\text { Compressive } \\
\text { strength } \\
(\mathrm{MPa})\end{array}$ & $\begin{array}{c}\text { Flexural } \\
\text { strength } \\
(\mathrm{MPa})\end{array}$ \\
\hline \multirow{7}{*}{$\mathrm{A} 1$} & 0 & 2.10 & 0.9624 & 6.65 & 67.4 & 7.06 \\
\hline & 50 & 2.10 & 0.9432 & 5.51 & 67.1 & 6.86 \\
\hline & 100 & 2.11 & 0.9527 & 4.84 & 64.7 & 6.71 \\
\hline & 150 & 2.13 & 0.9365 & 4.19 & 64.0 & 6.36 \\
\hline & 200 & 2.15 & 0.9255 & 3.36 & 62.0 & 6.00 \\
\hline & 250 & 2.17 & 0.9736 & 2.74 & 59.2 & 5.58 \\
\hline & 300 & 2.20 & 0.9718 & 2.41 & 55.5 & 5.10 \\
\hline \multirow{7}{*}{$\mathrm{A} 2$} & 0 & 2.11 & 0.9367 & 6.79 & 67.6 & 7.15 \\
\hline & 50 & 2.12 & 0.9284 & 6.18 & 67.3 & 6.94 \\
\hline & 100 & 2.12 & 0.9273 & 5.42 & 64.9 & 6.80 \\
\hline & 150 & 2.14 & 0.9198 & 4.70 & 64.2 & 6.44 \\
\hline & 200 & 2.16 & 0.9324 & 3.77 & 62.2 & 6.08 \\
\hline & 250 & 2.19 & 0.9563 & 3.08 & 59.4 & 5.65 \\
\hline & 300 & 2.21 & 0.9497 & 2.70 & 55.7 & 5.16 \\
\hline \multirow{7}{*}{ A3 } & 0 & 2.11 & 0.9564 & 6.84 & 67.8 & 7.24 \\
\hline & 50 & 2.12 & 0.9275 & 6.36 & 67.5 & 7.03 \\
\hline & 100 & 2.13 & 0.9389 & 5.57 & 65.1 & 6.88 \\
\hline & 150 & 2.15 & 0.9567 & 4.45 & 64.3 & 6.52 \\
\hline & 200 & 2.16 & 0.9657 & 3.72 & 62.2 & 6.15 \\
\hline & 250 & 2.18 & 0.9481 & 3.03 & 59.5 & 5.67 \\
\hline & 300 & 2.21 & 0.9219 & 2.66 & 55.9 & 5.15 \\
\hline \multirow{7}{*}{$\mathrm{A} 4$} & 0 & 2.13 & 0.9728 & 8.55 & 68.0 & 7.74 \\
\hline & 50 & 2.13 & 0.9658 & 7.95 & 67.7 & 7.52 \\
\hline & 100 & 2.15 & 0.9290 & 6.96 & 65.3 & 7.36 \\
\hline & 150 & 2.16 & 0.9309 & 5.57 & 64.6 & 6.97 \\
\hline & 200 & 2.18 & 0.9482 & 4.65 & 62.5 & 6.58 \\
\hline & 250 & 2.20 & 0.9193 & 3.80 & 59.7 & 6.07 \\
\hline & 300 & 2.22 & 0.9571 & 3.32 & 55.9 & 5.58 \\
\hline \multirow{7}{*}{ A5 } & 0 & 2.14 & 0.9674 & 10.75 & 69.9 & 7.91 \\
\hline & 50 & 2.15 & 0.9329 & 10.25 & 69.6 & 7.68 \\
\hline & 100 & 2.16 & 0.9198 & 9.03 & 67.2 & 7.52 \\
\hline & 150 & 2.17 & 0.9437 & 7.50 & 66.4 & 7.13 \\
\hline & 200 & 2.19 & 0.9522 & 6.17 & 64.3 & 6.72 \\
\hline & 250 & 2.21 & 0.9346 & 5.14 & 61.5 & 6.25 \\
\hline & 300 & 2.23 & 0.9633 & 4.27 & 57.6 & 5.77 \\
\hline
\end{tabular}

The image is successively divided into $c$ aliquots and is rounded (usually takes 2,3 , or 5 ); we use programming to convert digital images into binary image, extract digital matrix, and analyze and calculate the fractal. The calculation block diagram is shown in Figure 4.

Concrete aggregate interface shape is very irregular, whose surface of microscopic and macroscopic crack is uneven. The crack path is irregular, showing fractal characteristic. We can use fractal geometry to describe the crack irregularities and crack surface roughness [28]. In the macro- and microcracks of concrete fractal analysis, we need to process and analyze photos taken from the optical microscope or scanning electron microscope and convert graphic images into digital images. We can realize the transformation with modern digital image processing technology. Since the digital images captured are usually saved as matrix through sampling and quantization, we can extract useful information by processing. Figure 5 shows the cracks of ASC under freeze-thaw cycles, and Figure 6 shows the binary graph calculated by the method above. 


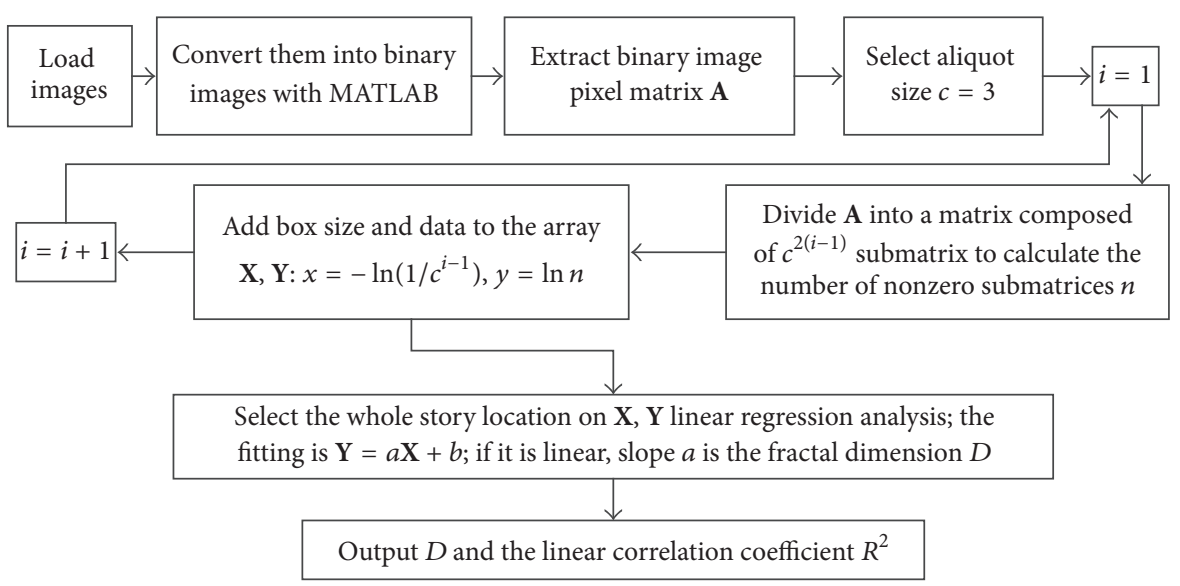

FIGURE 4: Fractal dimension calculation process.

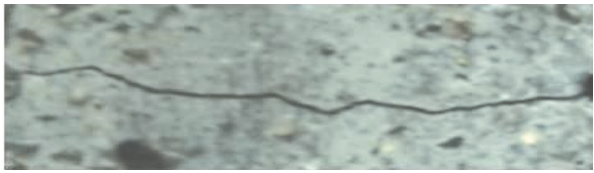

FIGURE 5: ASC cracking figure.

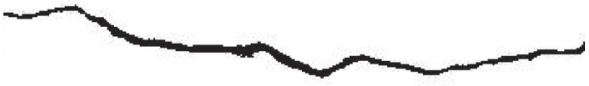

FIGURE 6: ASC cracking binary image.

\subsubsection{Prefreeze and Postthaw ASC Macroscopic Crack Fracture} Surface Fractal Analysis. Figures 7 and 8 show macroscopic cracks left after fracture toughness test before and after freezing and thawing; it can be seen through contrast that the specimen cracks before freeze-thaw extend along the direction of the force gently, and the curve has more twists and turns after freezing and thawing. Figures 9 and 10 are simplified binary diagrams of concrete fracture path around freezing and thawing. By calculating, the prefreeze fractal dimension $D$ is 1.10 and correlation coefficient $R^{2}$ is 0.9823 ; postthaw fractal dimension $D$ is 1.33 and correlation coefficient $R^{2}$ is 0.9863 . The results show that fractal theory is applicative in the study of ASC's crack surface.

3.3. Postthaw ASC Microcracks Fractal Analysis. Figure 11 is an ASC internal microstructure SEM photograph after freezing and thawing; from the photos you can clearly see the internal microcracks. After treatment, we get the internal microcracks binary image (Figure 12). By calculation using the method mentioned in this paper, fractal dimension $D$ is 1.37 and correlation coefficient $R^{2}$ is 0.9820 .

We did fractal calculations to fracture toughness of groups A1 A5 after 0, 50, 100, 150, 200, 250, and 300 freezethaw cycles. The measured fractal dimensions are shown in

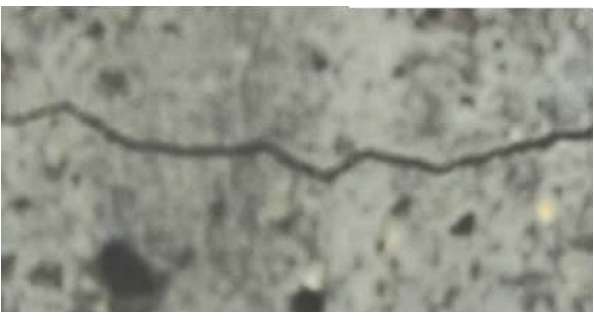

Figure 7: Prefreeze cracking path.

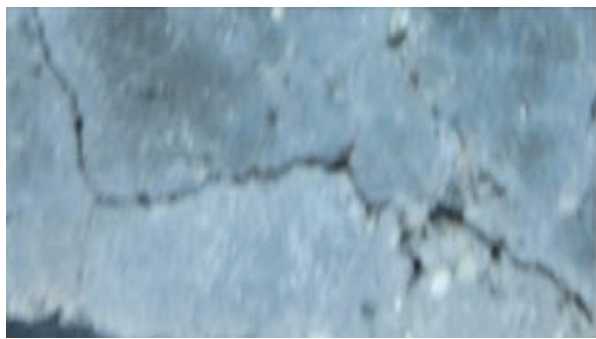

FIGURE 8: Postthaw cracking path.

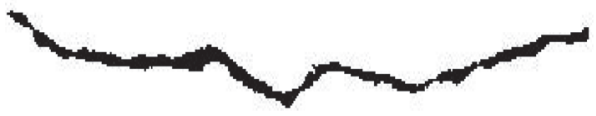

Figure 9: Prefreeze cracking path binary image.

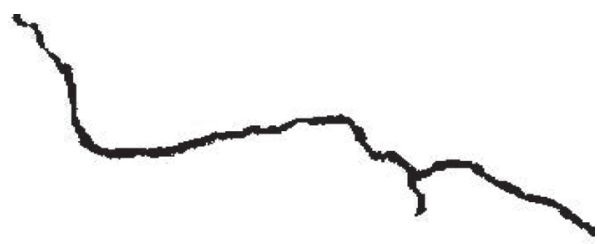

FIgURE 10: Postthaw cracking path binary image. 


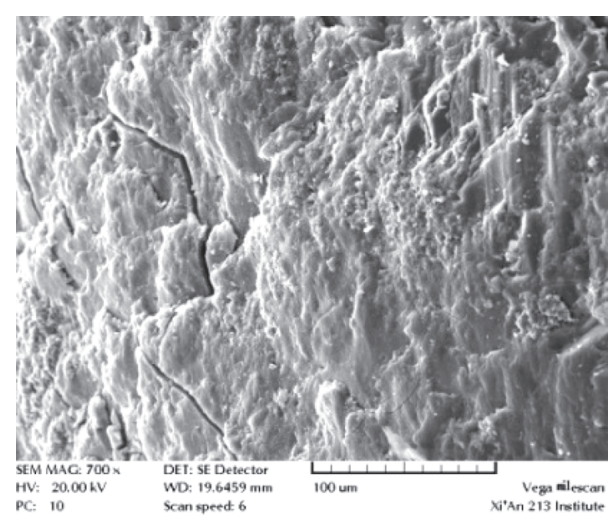

FIGURE 11: ASC internal microcracks under freeze-thaw cycles.

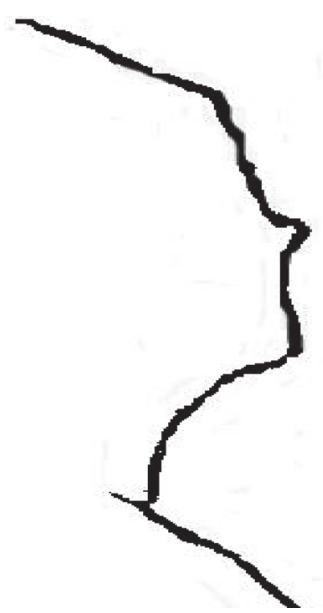

FIGURE 12: ASC internal microcracks binary image under freezethaw cycles.

Table 2. From fractal dimension linear regression in Table 2, each group of ASC fractal dimension is visible. It is feasible to evaluate ASC fracture behaviour under freeze-thaw cycles using fractal theory.

\section{ASC Characteristics and Fracture Surface Fractal Dimension Correlation Analysis}

4.1. ASC Fracture Toughness and Fractal Dimension Correlation Analysis. Section of concrete is not a plane, with projections and depressions; these features reflect the effect of fracture energy dissipation and microstructure damage during concrete fracture. With different degrees of freezing and thawing, the actual surface area of the fracture surface and roughness are different, showing different fracture toughness and different fractal dimension. Through the fractal study on fracture surface, relationship between fractal dimension and fractal parameter can be established. Figures 13-17 show tested and fitted values of fracture toughness and fractal dimension under 0 300 freeze-thaw cycles. It can be seen that the value is between 2.10 and 2.23. With freeze-thaw

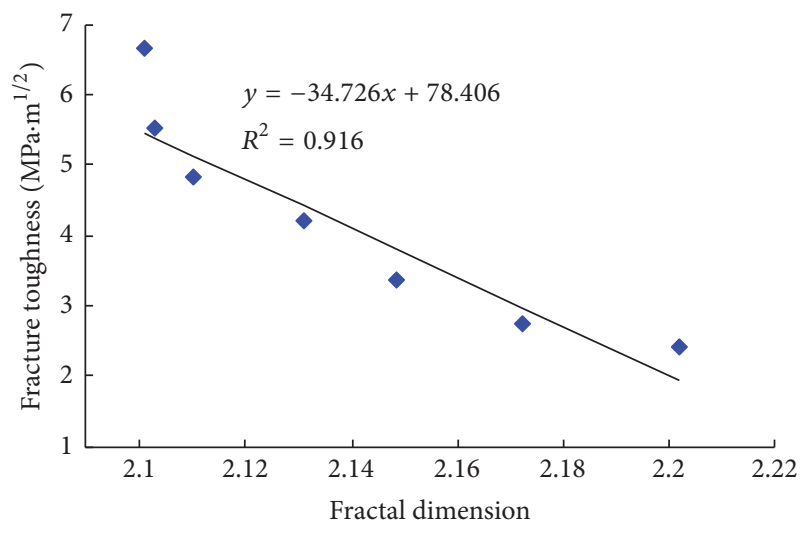

FIGURE 13: A1 fracture toughness versus fractal dimension.

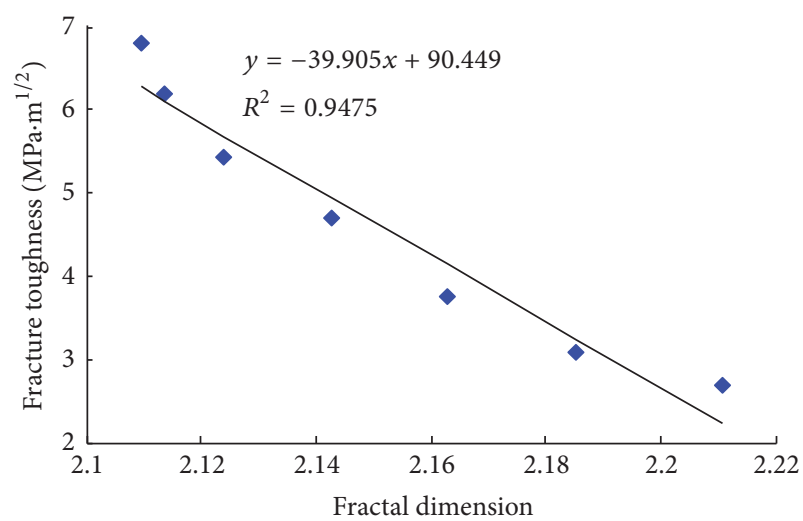

FIGURE 14: A2 fracture toughness versus fractal dimension.

cycle time increasing, ASC fracture toughness falls and fractal dimension increases; there is a good linear relationship. Five groups' ASC correlation coefficients are above 0.9 . This indicates that fractal dimension changes reflect changes in mechanical properties of ASC.

With the good linear correlation between fractal dimension and fracture toughness, when raw material and mix proportion are invariant, we can deduce ASC fracture toughness with the fractal dimension of fracture surface after freezethaw cycles. Fractal theory and fracture mechanics can be combined, characterizing ASC fracture behaviour after freezing and thawing damage. Fractal theory to study ASC under freezing and thawing is reasonable and has some practical engineering value.

4.2. Relationship between Fractal Dimension of Fracture Surface and Material Composition. ASC fracture characteristic is mainly influenced by factors such as sol ratio, the amount of slag, and raw nature of the materials, and the fractal dimension changes with material composition. To study the impact of ASC fracture surface on mechanical properties, influence of $\mathrm{A} / \mathrm{S}$ and the amount of slag on fractal dimension are studied.

4.2.1. Relationship between $D$ and A/S under Freeze-Thaw Cycles. Figure 18 shows the diagram fractal dimension 


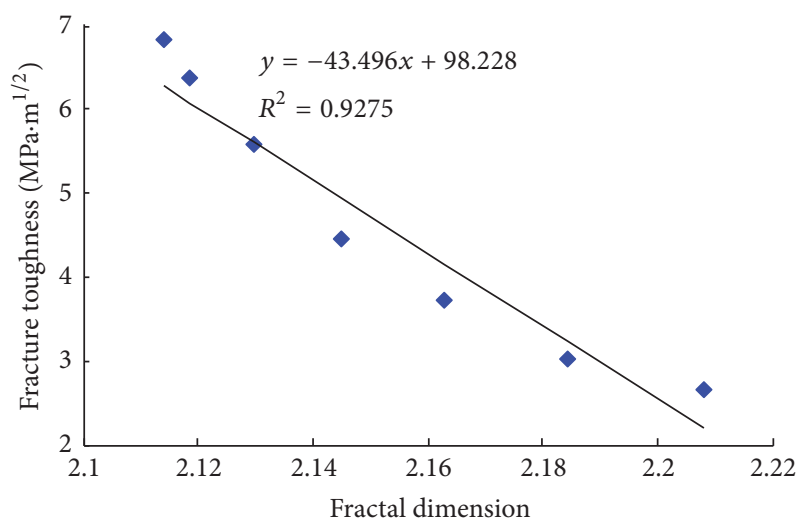

FIGURE 15: A3 fracture toughness versus fractal dimension.

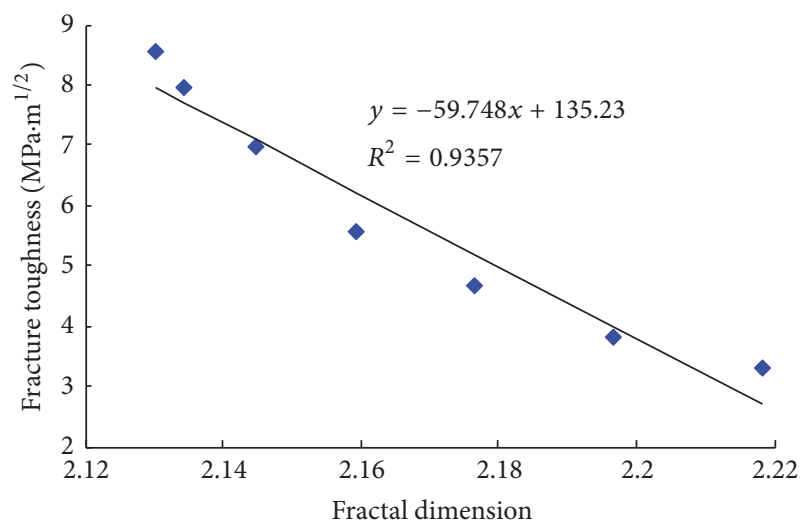

FIGURE 16: A4 fracture toughness versus fractal dimension.

changing with sol ratio; as can be seen, $D$ decreases with sol ratio. The main reason is when other conditions are certain, density inclement increases with lower sol ratio; then the strength of ACS material increases, but the fragility also increases unfortunately. Then, compressing after freeze-thaw cycles generates internal cracks more easily, which can be reflected from increase of fractal dimension of fracture surface.

4.2.2. Relationship between D and Slag Content under FreezeThaw Cycles. Figure 19 shows the diagram fractal of dimension changing with slag content. As can be seen, $D$ decreases with slag content; with more slag, $D$ is smaller. Under the condition that $\mathrm{A} / \mathrm{S}$ and other mix proportions are equal, more slag in unit volume concrete causes less coarse aggregate content, joint surface in cement is less, and the cement is more compacted undoubtedly. Higher degree compaction signifies less inner crack; then $D$ becomes smaller.

\section{Conclusions}

In this paper, the fractal analysis of ASC fracture surfaces is preliminary studied; aimed at the two-dimensional digital image characteristics, through digital fractal process of ASC crack, macro- and microcracks fractal analysis before and

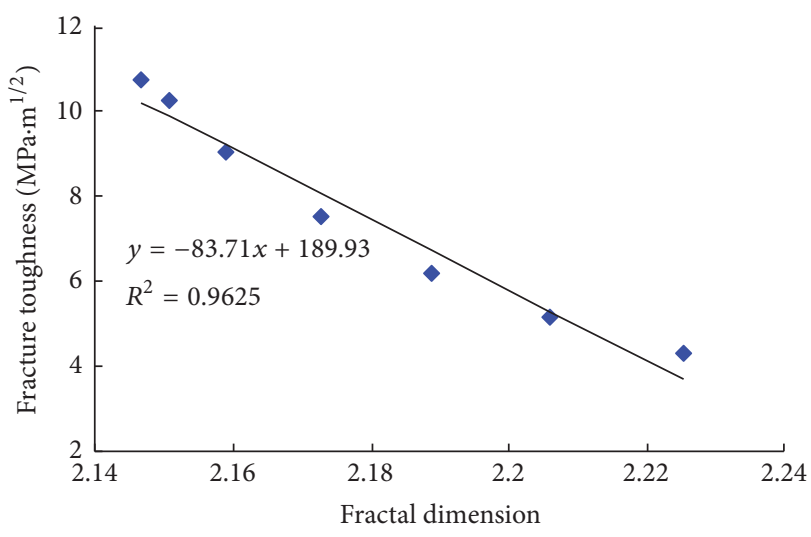

Figure 17: A5 fracture toughness versus fractal dimension.

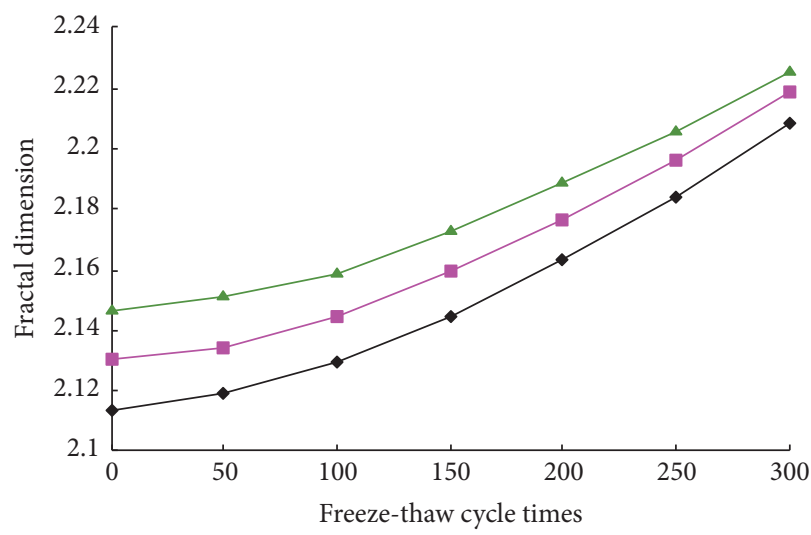

Sol ratio

$-0.54$

$-0.56$

$\multimap 0.58$

FIGURE 18: Relationship between A/S and dimension.

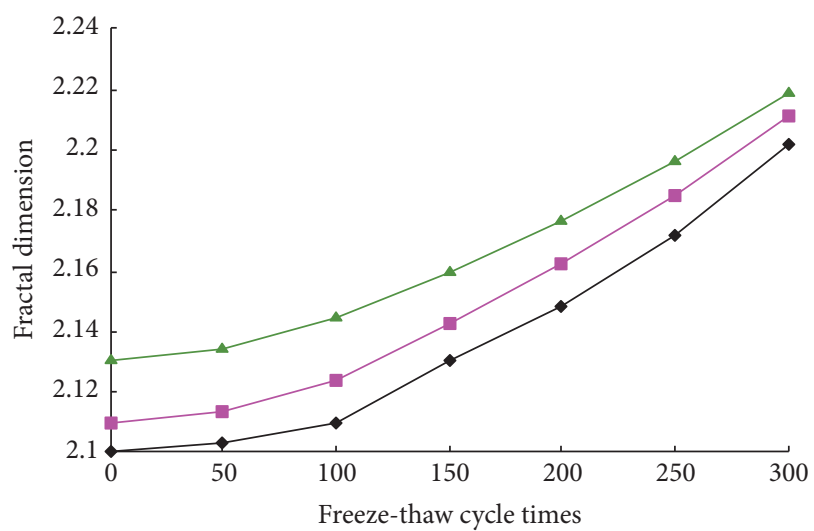

$$
\begin{aligned}
& \text { Slag content } \\
& -400 \mathrm{~kg} / \mathrm{m}^{3} \\
& \square 420 \mathrm{~kg} / \mathrm{m}^{3} \\
& \longrightarrow 440 \mathrm{~kg} / \mathrm{m}^{3}
\end{aligned}
$$

FIGURE 19: Relationship between slag content and dimension. 
after freezing and thawing is done, revealing relationship between fracture toughness and fractal dimension and relationship between fracture surface fractal dimension and material composition. ASC fracture surface fractal characteristics are studied before and after freeze-thaw cycles; the results are as follows:

(1) By calculating fractal dimension $D$ of fracture surface before and after freeze-thaw cycles for ASC using the method mentioned in this paper, all correlation coefficients are above 0.9 . The results show that fractal theory is applicative in the study of ASC's crack surface.

(2) By fracture surface macro- and microcrack fractal analysis before and after freeze-thaw cycles, the law of crack fractal dimension is established. After comparing macroscopic cracks left by fracture toughness tests before and after freezing and thawing, it can be seen that specimen crack before freeze-thaw extends along the direction of the force gently and shows more twists and turns after freezing and thawing; the fractal dimension $D$ also increases from 1.10 to 1.33; SEM internal microcracks' $D$ is 1.37 after freezing and thawing.

(3) The fractal dimension under freeze-thaw cycles is given; fractal dimension of 0 to 300 times freeze-thaw cycles is between 2.10 and 2.23.

(4) Relationship between ASC fracture surface fractal dimension and fracture toughness is established. With freeze-thaw times increasing, ASC fracture toughness decreases and fractal dimension increases; the fractal dimension and fracture toughness have a good linear relationship. The fractal dimension can reflect the toughening effect of ASC; it is feasible to evaluate ASC fracture behaviour with the fractal theory; the ASC fracture surface fractal dimension after freezing and thawing can be applied to deduce its fracture toughness.

(5) The relationship between ASC fracture surface fractal dimension and material composition is established. The fractal dimension shows a substantially monotonous growth trend with $\mathrm{A} / \mathrm{S}$ or slag content; the bigger the A/S or slag content is, the lower the fractal dimension tends to be.

\section{Conflicts of Interest}

The authors declare that they have no conflicts of interest.

\section{Acknowledgments}

The authors thank Dr. Yawei Fu and Dr. Qixuan Li for excellent technical support to this manuscript.

\section{References}

[1] B. B. Mandelbrot, The Fractal Geometry of Nature, W.H. Freeman and Company, New York, NY, USA, 1983.
[2] L. J. Hadjileontiadis and E. Douka, "Crack detection in plates using fractal dimension," Engineering Structures, vol. 29, no. 7, pp. 1612-1625, 2007.

[3] J. J. Mecholsky Jr., "Estimating theoretical strength of brittle materials using fractal geometry," Materials Letters, vol. 60, no, 20, pp. 2485-2488, 2006.

[4] J. He and C. H. Yang, "Research on the pore structure of alkalislag cement stone activated with water glass," Advanced Materials Research, vol. 194-196, pp. 899-903, 2011.

[5] A. Yan, K.-R. Wu, D. Zhang, and W. Yao, "Influence of concrete composition on the characterization of fracture surface," Cement and Concrete Composites, vol. 25, no. 1, pp. 153-157, 2003.

[6] V. Mechtcherine, "Fracture mechanical behavior of concrete and the condition of its fracture surface," Cement and Concrete Research, vol. 39, no. 7, pp. 620-628, 2009.

[7] V. E. Saouma, C. C. Barton, and N. A. Gamaleldin, "Fractal characterization of fracture surfaces in concrete," Engineering Fracture Mechanics, vol. 35, no. 1-3, pp. 47-53, 1990.

[8] M. A. Issa and A. M. Hammad, "Assessment and evaluation of fractal dimension of concrete fracture surface digitized images," Cement and Concrete Research, vol. 24, no. 2, pp. 325-334, 1994.

[9] H. Nagahama, "A fractal criterion for ductile and brittle fracture," Journal of Applied Physics, vol. 75, no. 6, pp. 3220-3222, 1994.

[10] A. Yan, K.-R. Wu, D. Zhang, and W. Yao, "Effect of fracture path on the fracture energy of high-strength concrete," Cement and Concrete Research, vol. 31, no. 11, pp. 1601-1606, 2001.

[11] M. A. Issa, M. A. Issa, M. S. Islam, and A. Chudnovsky, "Fractal dimension-a measure of fracture roughness and toughness of concrete," Engineering Fracture Mechanics, vol. 70, no. 1, pp. 125137, 2003.

[12] R. Vidya Sagar and B. K. Raghu Prasad, "Fracture analysis of concrete using singular fractal functions with lattice beam network and confirmation with acoustic emission study," Theoretical and Applied Fracture Mechanics, vol. 55, no. 3, pp. 192205, 2011.

[13] Y. Fu, L. Cai, and W. Yonggen, "Freeze-thaw cycle test and damage mechanics models of alkali-activated slag concrete," Construction and Building Materials, vol. 25, no. 7, pp. 31443148, 2011.

[14] M. Šejnoha, M. Brouček, E. Novotná, Z. Keršner, D. Lehký, and P. Frantík, "Fracture properties of cement and alkali activated fly ash based concrete with application to segmental tunnel lining," Advances in Engineering Software, vol. 62-63, pp. 61-71, 2013.

[15] L. Cai, H. Wang, and Y. Fu, "Freeze-thaw resistance of alkali-slag concrete based on response surface methodology," Construction and Building Materials, vol. 49, pp. 70-76, 2013.

[16] P. Sun and H.-C. Wu, "Chemical and freeze-thaw resistance of fly ash-based inorganic mortars," Fuel, vol. 111, pp. 740-745, 2013.

[17] Q. Li, L. Cai, Y. Fu, H. Wang, and Y. Zou, "Fracture properties and response surface methodology model of alkali-slag concrete under freeze-thaw cycles," Construction and Building Materials, vol. 93, pp. 620-626, 2015.

[18] H. Zhang, Fractal Fracture Behavior of Concrete and Damage Constitutive Study, South China University of Technology, Guangzhou, China, 2010.

[19] W. Guo, H. Qin, and H. Chen, "Fractal theory and other applications in the study of concrete materials," Qin H and Chen H, vol. 38, pp. 1362-1369, 2010. 
[20] H. Hu, Q. Zhang, and T. Ding, "Research on concrete mechanical properties based on fractal theory," Concrete, vol. 248, pp. 31-34, 2010.

[21] S. Erdem and M. A. Blankson, "Fractal-fracture analysis and characterization of impact-fractured surfaces in different types of concrete using digital image analysis and 3D nanomap laser profilometery," Construction and Building Materials, vol. 40, pp. 70-76, 2013.

[22] J. Konkol and G. Prokopski, "Fracture toughness and fracture surfaces morphology of metakaolinite-modified concrete," Construction and Building Materials, vol. 213, no. 1, pp. 638-648, 2016.

[23] DL/T 5332-2005 《Norm for fracture test of hydraulic concrete》.

[24] S. Xu and H. W. Reinhardt, "A simplified method for determining double-K fracture parameters for three-point bending tests," International Journal of Fracture, vol. 104, no. 2, pp. 181-209, 2000.

[25] S. Xu, Z. Wu, and S. Ding, "A practical analytical approach to the determination of double-K fracture parameters of concrete," Engineering Mechanics, vol. 20, no. 3, pp. 54-62, 2003.

[26] Y. Fu, Study on ASC fracture damage and self-healing performance exposed to freeze-thaw cycles [Doctoral, thesis], Airforce Engineering University, Xian, China, 2012.

[27] R. Peng, H. Xie, and Y. Ju, "Computation method of fractal dimension for 2-D digital image," Journal of China University of Mining Technology, vol. 33, pp. 19-24, 2004.

[28] M. Cao, Q. Ren, and A. Zhai, "Fractal characteristics experimental analysis of concrete structural damage," Rock and Soil Mechanics, vol. 26, pp. 1570-1574, 2005. 

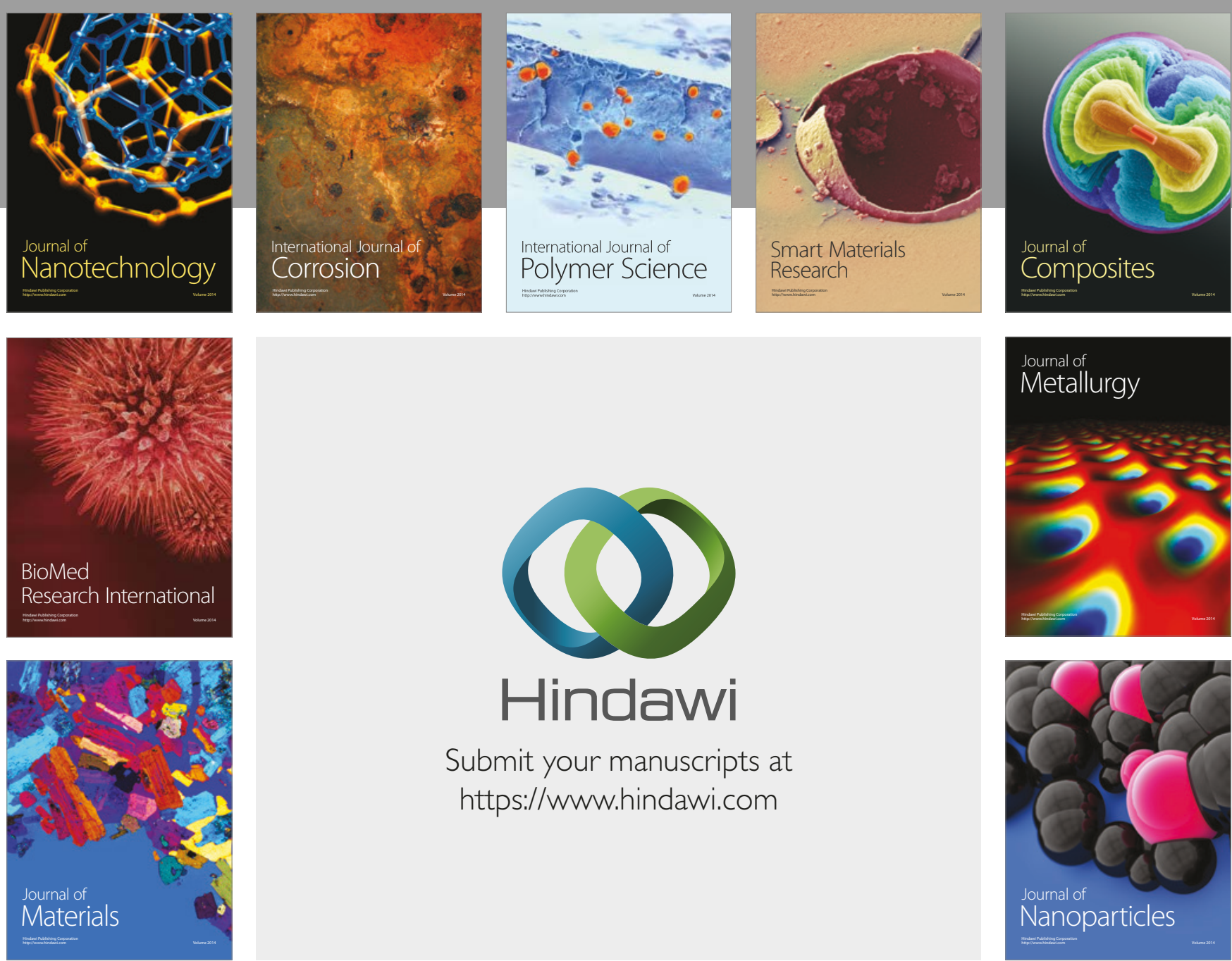

\section{Hindawi}

Submit your manuscripts at

https://www.hindawi.com
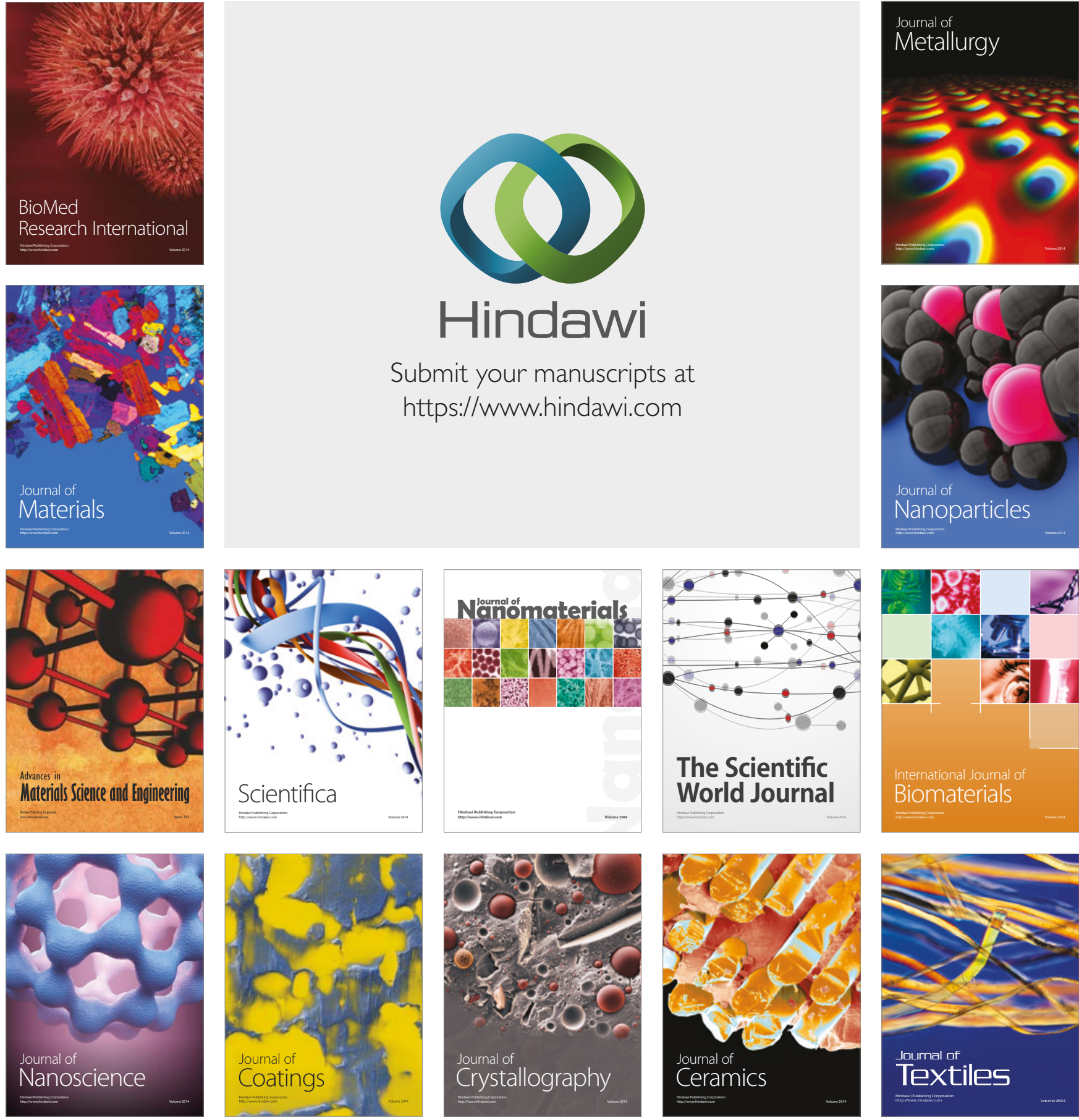

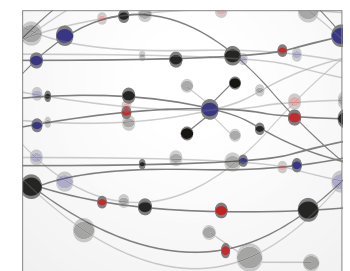

The Scientific World Journal
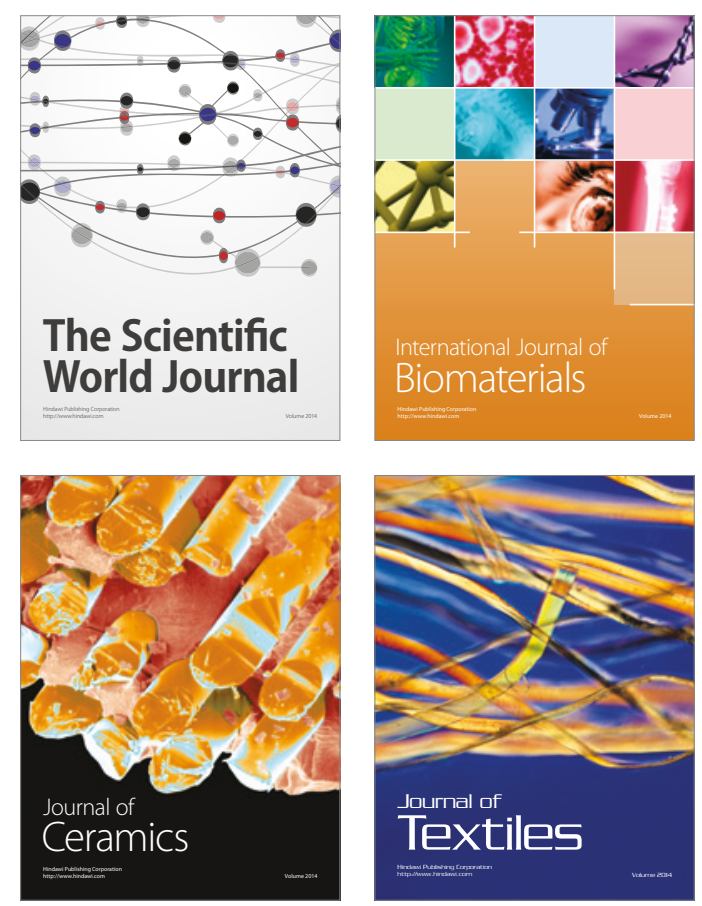